\title{
ON SUBJECT TO FORECAST CAUSAL FACTORS FOR SPONTANEOUS FIRES IN COAL MINES
}

\section{К ВОПРОСУ ПРОГНОЗИРОВАНИЯ УСЛОВИЙ ВОЗНИКНОВЕНИЯ ЭНДОГЕННЫХ ПОЖАРОВ В УГОЛЬНЫХ ШАХТАХ}

\section{Vadym Tarasov ${ }^{1}$}

DOI: https://doi.org/10.30525/978-9934-26-001-8-2-11

\begin{abstract}
Regulations for assessment of workable bed hazardous characteristics during the mining operations include the coal metamorphic grade classification indices borrowed from the industrial classifications without any proper scientific justification. For true forecasting the workable bed hazardous characteristics during the mining operations, the method to detect the metamorphic grades by changing the content of main components and moisture in the organic matter has been developed.

Purpose. Development of the forecasting technique logical sequence for workable bed liability to spontaneous ignition in different stages of coal metamorphic conversion and their chemical activity during the mining operations.
\end{abstract}

Methods. They are based on assumption of spontaneous fires with three blocks of factors independent of each other. The factors of block one describe the chemical activity of coals. They are defined by their elemental composition and properties at the different stages of bed metamorphic conversion. The second group of impacting factors characterizes the mining and geological conditions of bedding. It includes the coal beds position relative to each other, their occurrence depth, thickness and degree of inclination, presence of geological breaches and adjacent strata properties. The factors of block three is independently connected with the mining operation conditions. The forecasting technique for workable bed liability to spontaneous ignition avoids any stable correlation relationships between

\footnotetext{
${ }^{1}$ Candidate of Technical Sciences, Associate Professor, Associate Professor of the Department of Mining,

Volodymyr Dahl East Ukrainian National University, Ukraine

(C) Vadym Tarasov
} 
the factor parameters of three blocks under consideration. It allows separate consideration of each block and avoid their random correlations with factors of other blocks.

Results. The statistical processing result analysis of more than 1000 coal samples with carbon content of $80 \div 94 \%$ has allowed establishing the relationship between the organic matter components and total moisture, as well as their share of participation in carbonization process that reflects the Donets Basin coal metamorphic conversions. Compliance of the initial data with analytical data of different coal deposits has been established. For the first time, the technique has been developed; and organic matter separate components and total moisture participation shares in coal carbonization process indices creation, which is one of evaluation criteria for workable bed metamorphic conversion degree for different deposits, have been established.

The revealed regularities of change ambiguity for organic matter elemental composition components and their different participation shares together with the moisture in carbonization process have allowed establishing the distinctive features of the coal metamorphic conversion different stages for true forecasting the workable bed hazardous characteristics during the mining operations. In the course of this approach, the real chemical activity of coals is established by their elemental composition in different stages of bed metamorphic conversions; certain places of long-term contacts between the mine air and coal are differentially forecasted in the mine field. It enables the enhanced automated monitoring of mine air condition and revealing of spontaneous combustion places in early stages of their creation.

Scientific novelty. The pattern of change for classification indices of coal industrial classification has been revealed to establish the workable bed hazardous characteristics during the mining operations.

Practical relevance. Opportunity to improve the regulatory framework for safe processing of workable beds by establishing the interrelation between fossil coal metamorphic conversions and their elemental composition.

\section{1. Введение}

Проблема прогнозирования эндогенных пожаров в угольных шахтах Донбасса особенно остро проявилась около 50 лет назад [1]. Такие пожары составляли более $30 \%$ от общего количества подземных по- 
жаров. Самовозгорание в подземных выработках рассматривалось как явление, обусловленное генетическим фактором образования углей, а также горно-геологическими условиями ведения горных работ. Исследования проводились статистическими, химическими и физическими методами. Статистический метод использовался для изучения связей между эндогенной пожароопасностью и остальными влияющими факторами. Такими считались степень углефикации, содержание серы, горно-геологические и горнотехнические условия ведения горных работ. Химические методы применялись для исследования пластово-дифференциальных проб углей. Физические методы (кристалло-оптический и рентгеноструктурный) были выбраны для изучения дисульфидов и определения вещественного состава углей.

В этот период из 661 разрабатываемого пласта шахтами Украинского Донбасса в категорию склонных к самовозгоранию было отнесено 132. Наиболее опасными являлись пласты $m_{3}, l_{1}, l_{3}$ и $k_{5}[2]$.

К категории опасных, при всех видах исследований, относили платы, где официально был зарегистрирован хотя бы один случай эндогенного пожара.

Этот принцип отнесения шахтопластов в категорию опасных сохранился до настоящего времени. В дополнение к нему во всех случаях отработки шахтопластов каменных углей (кроме антрацитов) необходимо разрабатывать проекты, касающиеся предупреждения пожаров от самовозгорания угля [3]. В связи с этим во многих случаях требуются не всегда обоснованные большие затраты денежных средств, труда и времени на проведение профилактических мероприятий. Подтверждением этому служат данные [4] о количестве эндогенных пожаров, произошедших за последние 20 лет. В таблице 1 приведены систематизированные сведения о 66 шахтопластах. За рассматриваемый период произошло всего 217 эндогенных пожаров. Наиболее часто (более 10) они происходили на девяти шахтопластах. От одного до десяти случаев эндогенные пожары наблюдались при отработке 28 шахтопластов, а на 29 - они отсутствовали. К наиболее опасным шахтопластам в современных шахтах относятся $k_{7}, k_{8}^{H}, m_{3}, l_{1}, l_{3}$ и $l_{7}$.

Пласты $m_{3}, l_{1}$ и $l_{3}$ за прошедшие 50 лет сохранили повышенную склонность к самовозгоранию, а применяемая нормативная база практически не повлияла на снижение количества происходящих эндо- 


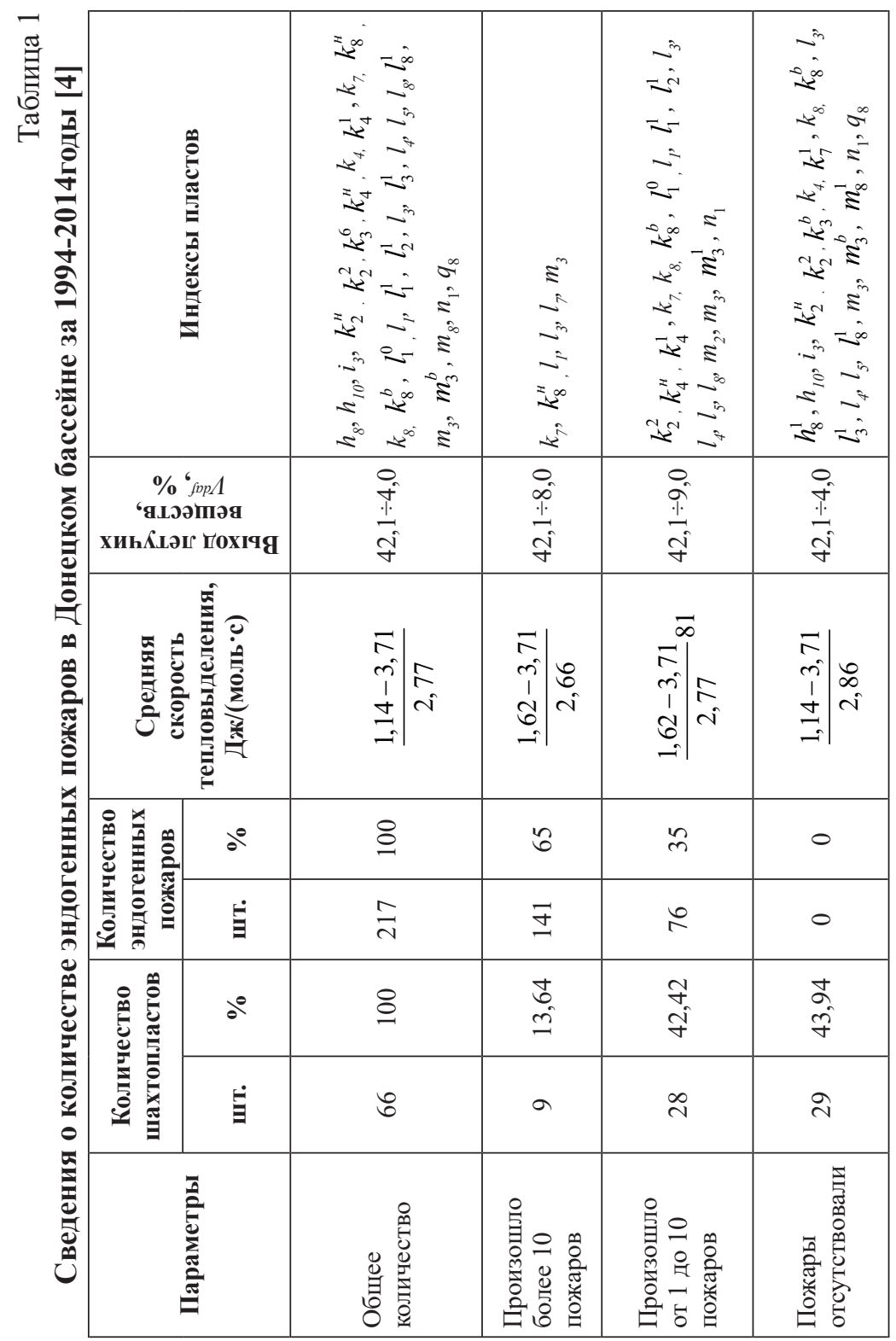


генных пожаров при отработке этих пластов. Особоопасные пласты составляют около $14 \%$ от всех разрабатываемых в настоящее время. На их долю приходится $65 \%$ произошедших пожаров. Это свидетельствует о сохранившейся до настоящего времени актуальности достоверного прогноза пожароопасности шахтопластов.

\section{2. Показатели метаморфизма для установления эндогенной пожароопасности шахтопластов}

Недостатки современного прогноза склонности шахтопластов к самовозгоранию [5] выявлены на основании анализа методики определения химической активности углей [6]. Химическая активность - наиболее весомая составная часть эндогенной пожароопасности и склонности угля к самовозгоранию. Она является не единственным фактором, способствующим возникновению эндогенных пожаров. Для достоверного прогноза склонности угля к самовозгораемости, а шахтопластов к возникновению эндогенных пожаров, необходимо дополнительно к химической активности углей рассматривать горно-геологические и горнотехнические условия ведения горных работ. Возникновение очагов самовозгорания в разных частях шахтного поля связано с условиями нахождения угля в горных выработках и некоторых зонах пластов, подверженных изменению их природного состояния. Процессы самовозгорания происходят под воздействием характерных для этих очагов факторов, которые могут существенно активизировать или тормозить эти процессы [7].

По данным геологомаркшейдерской документации и актам расследования причин самовозгорания угля при отработке 161 шахтопласта в Донбассе установлены горно-геологические и горнотехнические причины возникновения эндогенных пожаров [8]. Наибольшее их количество произошло при выемке пластов не на полную мощность (42\%), а также при подработке или надработке сближенных пластов, попадающих в зону сдвижения пород с разрывом их сплошности под влиянием очистных выработок (38\%). В скоплениях отбитого угля зафиксировано $14 \%$, а в целиках, оставленных в выработанном пространстве - всего $6 \%$ от общего количества эндогенных пожаров. Приведенная статистика свидетельствует о важной роли в возникновении эндогенных пожаров горно-геологических и горнотехнических факторов, которые 
в неполной мере учитываются нормативными документами [5;9]. Установлены [6] значительные отличия между кинетикой окисления угля, протекающей в импульсном реакторе в лаборатории и в шахте. Используемый комплексный показатель пожароопасности пластов не учитывает влажность, газоносность и теплопроводность угля. Устранению указанных недостатков посвящены работы $[8 ; 10 ; 11]$. Они связаны с уточнением комплексных показателей, а вместе с ними и вероятности возникновения эндогенных пожаров. Количественное значение вероятности возникновения пожара указывает на возможность существования реальной опасности, но не определяет факторы, вызывающие самовозгорание углей в конкретных условиях угольных шахтах. В работе [10] для решения теоретической задачи тепломассообмена не учитывались горно-геологические и горнотехнические условия нахождения угля в горных выработках. К рассмотрению приняты дробимость угля, его плотность и газоносность. Показатели дробимости, определенные в лабораторных условиях существенно отличаются от фракционного выхода угля в производственных условиях. Он связан со способами отбойки угля и конструктивными особенностями выемочных механизмов. Плотность характеризует только одну из сторон метаморфических преобразований углей.

Влияние метаморфизма на самовозгораемость углей в работе [11] не принималось во внимание ни одним показателем. К анализу приняты мощность разрабатываемого пласта, угол его падения, скорость подвигания очистного забоя, размеры скопления угля, диаметр его частиц и наличие серы.

Несколько другая методика определения вероятности возникновения пожаров применена в работе [8]. В качестве показателей химической активности углей учитывалось наличие серы, зольность, марки угля (выход летучих веществ) и коэффициент диффузии кислорода в поры угля. Геологические условия учитывались мощностью разрабатываемого пласта и плотностью выемки угля (наличие нерабочих пластов - спутников). Горно-технические условия характеризовались скоростью подвигания очистного забоя, расходом воздуха в рабочем пространстве лавы, наличием междуэтажных целиков, способами отбойки угля и управлением горным давлением. Каждая группа факторов оценивалась условными показателями весомости. Это не исключа- 
ет дополнительные погрешности, связанные с достоверностью выбора исходных влияющих факторов и расчетом их весомости.

В работах $[8 ; 10 ; 11]$ использованы факторы, определяющие комплексные показатели пожарной опасности шахтопластов. Наряду с этим во всех случаях получены близкие значения вероятности возникновения эндогенных пожаров. Это может свидетельствовать, о том, что выбранные факторы для расчёта комплексных показателей не в полной мере отражают склонность углей к их самовозгоранию. В первую очередь это связано с отсутствием в расчетах $[8 ; 10 ; 11]$ влияния влаги и достоверной оценки степени преобразования углей на разных стадиях метаморфизма пластов. Степень метаморфизма оценивалась [8] по их марочной принадлежности $(M)$ или выходу летучих веществ при термическом разложении углей без доступа воздуха $\left(V^{d a f}\right)$. Эти показатели позаимствованы, без должного научного обоснования, из промышленных классификаций углей [12; 13]. Они были искусственно подобраны в комплексе с другими показателями для характеристики потребительских свойств углей. Марки углей установлены для условного обозначения разновидностей углей, близких по генетическим признакам и основным энергетическим и технологическим характеристика [14].

Метаморфизм должен рассматриваться как превращение бурого угля последовательно в каменный уголь и антрацит в результате изменения химического состава, структуры и физических свойств угля в недрах преимущественно под влиянием повышенной температуры и давления [14]. Процессы метаморфизма углей в природных условиях достигали определенной степени преобразования органической массы при температурах не более $650^{\circ} \mathrm{C}$ [15]. Термическое же разложение углей согласно [16] производят при температуре $900^{\circ} \mathrm{C}$. По этой причине процессы температурного разложения углей являются очередной стадией их искусственного преобразования. Показатель $V^{d a f}$ не может в полной мере, характеризовать состав и свойства углей, находящихся в условиях действующей шахты. Показатель $V^{d a f}$, учитывая методику его определения [16], характеризует общую совокупность газообразных продуктов термического разложения без их идентификации, что делает практически невозможным установление влияния отдельных компонентов органического вещества на проявление его опасных свойств. Кроме этого, $V^{d a f}$ определяется на сухую беззольную массу, чем исклю- 
чается влияние влаги и минеральных примесей на склонность углей к самовозгоранию.

Согласно промышленным классификациям [12] при $V^{\text {daf }}<8 \div 10 \%$ угли относят к антрацитам. При таком подходе в экспериментальных исследованиях [6] антрацитовыми необходимо считать одиннадцать шахтопластов. Для них значения $V^{\text {daf }}$ находились в диапазоне $4 \div 10 \%$. По факту угли этих шахтопластов причислены к другим маркам [6]. По применяемому показателю $V^{d a f}$ они формально являются антрацитами и не относятся к самовозгораемым согласно нормативному документу [3]. За последние 20 лет при отработке таких шахтопластов возникло 24 эндогенных пожара [6]. Из них 21 авария на пласте $l_{1}$, уголь которого характеризовался значением $V^{d a f}=8 \%$. Приведенные факты свидетельствуют, что марочная принадлежность углей и выход летучих веществ не отражают, в полной мере, их склонность к самовозгоранию. По этой причине скорость тепловыделения, вычисленная по значению $V^{d a f}[6]$, не может быть объективным критерием склонности углей к самовозгоранию. Подтверждением этому являются данные о произошедших пожарах (табл. 1). Средняя скорость тепловыделения для девяти шахтопластов, где произошло более 10 пожаров, составляла 2,66 Дж/(моль'c). Значения этого показателя были несколько выше $(2,86$ Дж/(моль'c)) для 29 шахтопластов, при отработке которых эндогенные пожары отсутствовали. В обоих случаях скорость тепловыделения находилась в диапазоне $1,14 \div 2,86$ Дж/(моль с ). Приведенные факты свидетельствуют об имеющихся недостатках нормативной базы $[3 ; 5 ; 9]$ в части достоверного определения химической активности углей, характеризуемой разными стадиями метаморфических преобразований шахтопластов.

\section{3. Прогнозирование условий возникновения эндогенных пожаров в угольных шахтах}

Цель исследований разработать логическую последовательность методики прогноза склонности шахтопластов к возникновению эндогенных пожаров на разных стадиях метаморфических преобразований углей и их химической активности при ведении горных работ в шахтах. Химическая активность углей и склонность их к самовозгоранию определяется элементным составом и свойствами органического ве- 
щества, в том числе при наличии влаги и минеральных примесей на разных стадиях метаморфических преобразований шахтопластов.

Методика проведения исследований основана в предположении связи эндогенных пожаров с тремя блоками, факторов, независимых между собой. Факторы первого блока характеризуют химическую активность углей. Они определяются их элементным составом и свойствами на разных стадиях метаморфических преобразований пластов.

Вторая группа влияющих факторов характеризует горно-геологические условия залегания пластов. Она включает расположение угольных пластов относительно друг друга, глубину залегания, их мощность и угол падения, наличие геологических нарушений и свойства вмещающих пород. Третий блок факторов непосредственно связан с условиями ведения горных работ. Эндогенные пожары происходили в разных частях шахтных полей и на разных стадиях их отработки. Они возникали в пределах действующих выемочных участков (30\%) и после их отработки (25\%). В протяженных горных выработках происходило $15 \%$ от всего количества эндогенных пожаров, а в тупиковых выработках - 10\%. Возгорание в охранных целиках угля наблюдалось в 6\% случаев. В прочих местах произошло 16\% эндогенных пожаров [17]. Приведенные факты свидетельствуют, что эндогенные пожары происходили на всех стадиях эксплуатации угольного месторождения. Вероятность появления очагов самовозгорания возможно на любой из них. Это обуславливает необходимость учитывать влияние эксплуатационных факторов на протяжении всего времени отработки шахтного поля. На разных стадиях ведения горных работ к таким факторам могут относится схемы вскрытия шахтного поля, системы разработки, технология добычи угля и допустимые его потери, способы проведения выработок, схемы проветривания шахты, выемочных и подготовительных участков, способы управления горным давлением и т.д. Влияние эксплуатационных факторов и их количество зависит от предполагаемого места (расположения) очага самовозгорания угля в шахтном поле. Неизменным условием самовозгорания во всех случаях является контакт рудничного воздуха с углем и накопление тепла.

Методика прогноза склонности шахтопластов к самовозгоранию, исключает устойчивые корреляционные связи между параметрами факторов трех рассмотренных блоков. Это позволяет факторы каждого 
блока рассмотреть обособленно и исключить их случайные корреляционные связи с факторами других блоков.

К наиболее важным относятся факторы первого блока. Они определяют химическую активность углей на разных стадиях метаморфических преобразований шахтопластов. Стадии метаморфизма должны оцениваться по изменению элементного состава органического вещества. Основными его компонентами являются углерод $\left(C_{o}\right)$, водород $\left(H_{o}\right)$, азот $\left(N_{o}\right)$, сера $\left(S_{o}\right)$ и кислород $\left(O_{o}\right)$. К органической составляющей относится также содержание влаги $(W)$. Она является одним из критериев оценки степени метаморфизма шахтопластов [18; 19] и оказывает существенное влияние на процессы окисления углей [20]. Сумма компонентов $C_{o}, H_{o}, N_{o}, S_{o}, O_{o}$ и $W$ практически составляют около $100 \%$ органического вещества на всех стадиях метаморфических преобразований шахтопластов. Их соотношение, в основном, определяет химическую активность углей. При определении интенсивности возникновения эндогенных пожаров $\left(\lambda_{\phi}\right)$ согласно [8; 9] непосредственно не учитывается элементный состав органического вещества:

$\lambda_{\phi}=-0,008+0,029 m+0,0007 \alpha+0,008 S_{t}^{d}-0,0008 v_{o r}-0,0035 H g$,

где 0,008 - свободный член; $m$ - мощность пласта, м; $\alpha$ - угол падения пласта, град; $S_{t}^{d}$ - доля общей серы в угле, $\% ; v_{o r}$ - скорость подвигания очистного забоя, м/мес; $\mathrm{Hg}$ - диффузионное сопротивление, мм.

$$
H g=18 \cdot 10^{-4} \cdot k^{-1},
$$

$k$ - скорость химической реакции, $\mathrm{c}^{-1}$.

В рассматриваемо случае к статистической совместной обработке привлечены заведомо не коррелируемые между собой факторы $(m, \alpha$, $\left.S_{o}, v_{o r}, H g\right)$. Они не характеризуют изменение элементного состава и свойств шахтопластов на разных стадиях их метаморфических преобразований. По этой причине вероятность $(P)$ возникновения пожаров [8; 9] заведомо носит случайный характер для конкретных условий:

$$
P=1-\exp \left(\lambda_{\phi} \cdot \tau\right)
$$

где $\tau$ - время отработки выемочного поля (участка), мес.

В отличие от показателя $\lambda_{\phi}$ установлены тесные корреляционные связи между компонентами элементного состава органического вещества в процессе метаморфических преобразований шахтопластов на 
разных стадиях [7; 15]. Это дает основание при установлении химической активности углей использовать изменения соотношения между компонентами органического вещества $C_{o}, H_{o}, N_{o}, S_{o}, O_{o}$ и $W$. Изменение соотношения между компонентами под влиянием температуры и давления метаморфических процессов предопределяет и изменение физико-механических свойств углей. Это, в конечном итоге, отражается на устойчивости внутренней их структуры, и в конечном итоге влияет на химическую активность углей.

В первом блоке факторов, определяющих склонность углей к самовозгоранию, необходимо также учитывать роль минеральных примесей. Наличие серосодержащих минералов и общей серы в органическом веществе способствует возникновению очагов самовозгорания. Это подтверждается сравнением характеристик шахтопластов повышенной пожароопасности и не склонных к самовозгоранию [1]. Условия эксплуатации шахтопластов, на которых не было зарегистрирована ни одного пожара, практически не отличались марками углей, мощностью пластов, углами падений и тектонической нарушенностью от шахтопластов повышенной эндогенной пожароопасности (табл. 2). Главным отличительным признаком склонности шахтопластов к высокой пожароопасности являлось повышенное содержание серы $\left(S_{o}>3,0 \%\right)$.

Пожары отсутствовали при содержании серы менее $3 \%$, простом строении разрабатываемого пласта и малой тектонической нарушенности. Приведенный статистический материал свидетельствует, что эндогенные пожары происходят практически во всех горно-геологических условиях добычи угля подземным способом. Первопричиной склонности шахтопластов к повышенной самовозгораемости является изменение элементного состава органического вещества и минеральных примесей в процессе метаморфических преобразований.

Преобразования органического вещества под воздействием повышенных температур и давления носят многогранный характер. Векторное направление изменения состава органического вещества при усилении метаморфизма от бурых углей к каменным, а затем к антрацитам, характеризуется увеличением содержания углерода примерно с 70 до 97-98\%, и соответствующим сокращением суммы остальных компонентов [7; 15]. Содержание каждого из основных компонентов органического вещества $C_{o}, H_{o}, N_{o}, S_{o}, O_{o}$ и $W$ для конкретного шах- 
топласта определяется исходным их соотношением и условиями удаления флюидов при метаморфических процессах. Общая сумма содержания убывающих компонентов $\left(H_{o}, N_{o}, S_{o}, O_{o}, W\right)$ контролируется содержанием углерода $C_{o}$. Зависимость суммы основных компонентов $\left(H_{o}, N_{o}, S_{o}, O_{o}\right)$ от содержания углерода характеризуется по сути функциональной зависимостью [7; 15].

Таблица 2

Характеристика шахтопластов повышенной пожароопасности и не склонных к самовозгоранию согласно геолого-углехимической характеристики [1]

\begin{tabular}{|l|c|c|c|}
\hline $\begin{array}{c}\text { Показатель } \\
\text { пожароопасности }\end{array}$ & $\begin{array}{c}\text { Количество } \\
\text { рассмотренных } \\
\text { шахтопластов, } \\
\text { шт }\end{array}$ & $\begin{array}{c}\text { Шахтопласты } \\
\text { повышенной } \\
\text { эндогенной } \\
\text { пожароопасности }\end{array}$ & $\begin{array}{c}\text { Эндогенные } \\
\text { пожары } \\
\text { отсутствовали }\end{array}$ \\
\hline Марка угля & 440 & Д, Ж, К, ОС, Т & Д, Г, Ж, К, ОС, Т \\
\hline Общая сера $S_{\circ}, \%$ & 900 & $>3,0$ & $<3,0$ \\
\hline $\begin{array}{l}\text { Пощность } \\
\text { пластов, } m\end{array}$ & 900 & $>2,0$ & $\begin{array}{c}\text { средней и повы- } \\
(1,2 \div 3,5 \text { м); малой и } \\
\text { средней мощности } \\
(0,71 \div 3,5 \text { м) }\end{array}$ \\
\hline Угол падения, град & 440 & любой & $\begin{array}{c}\text { пологое залегание } \\
\left.\text { (до } 18^{\circ}\right)\end{array}$ \\
\hline $\begin{array}{l}\text { Нарушенность } \\
\text { месторождения }\end{array}$ & 160 & любая & $\begin{array}{c}\text { малая } \\
\text { тектоническая }\end{array}$ \\
\hline Строение пласта & 900 & любое & простое строение \\
\hline
\end{tabular}

Значение коэффициента корреляции $(r)$ составляет около $-0,99$. Индивидуальное сокращение содержания основных компонентов при увеличении $C_{\text {o }}$ происходит не так однозначно. Их связи, как правило, подчиняются нелинейным зависимостям и имеются в отдельных случаях аномальные отклонения некоторых основных компонентов от усредняющих кривых. Это свидетельствует об отличиях степени метаморфических преобразований конкретного шахтопласта от усредненных показателей. Следовательно, элементный состав и свойства таких шахтопластов будут отличаться от усредненных показателей. Эти индивидуальные отличия зависят от содержания каждого компонента в 
органическом веществе. В процессе метаморфизма содержание кислорода монотонно сокращается с 20-30\% практически до нуля. При увеличении содержания углерода примерно с 70 до 87-88\% содержание водорода остается неизменным и находится в диапазоне 4-6\%. Резкое его снижение до долей процента происходит при дальнейшем росте содержания углерода. Сокращение азота происходит при содержании углерода более 95\%. Процентное содержание серы практически не изменяется на всех стадиях метаморфизма. Для отдельных шахтопластов содержание общей серы может составлять менее одного процента. Имеются случаи максимального ее содержания до 10\%. Элементное индивидуальное содержание каждого компонента органического вещества характеризует определенную сторону метаморфического преобразования шахтопласта. Комбинации соотношения $C_{o}, H_{o}, N_{o}, S_{o}$, $O_{o}$ и $W$ формируют индивидуальные свойства шахтопластов, которые проявляются при ведении горных работ. Опыт отработки отдельных шахтопластов и накопленный современный статистический материал позволяют для установления химической активности использовать результаты анализа лабораторных проб угля с определением $C_{o}, H_{o}, N_{o}, S_{o}$ и $O_{o}$. Современная методика определения влаги в большинстве случаев связана с ее высушиванием до постоянного веса пробы угля. По этой причине показатель $W$ не всегда представляется возможным отнести к сухой беззольной массе органического вещества в совокупности с $C_{o}, H_{o}, N_{o}, S_{o}$ и $O_{o}$. Большинство компонентов органического вещества взаимнокоррелированы между собой. К ним относится и содержание влаги. Показатель $W$ зависит от содержания углерода [21], а также установлена нелинейная его связь с содержанием кислорода [22]. Это свидетельствует, что в первом блоке факторов, определяющих склонность углей к самовозгоранию необходимо рассматривать, как минимум, элементное соотношение между $C_{o}, H_{o}, N_{o}, S_{o}$ и $O_{o}$. Содержание каждого из этих компонентов индивидуально характеризует одну из сторон метаморфических процессов преобразования шахтопластов. Изменение их соотношения указывает на появление отличительных свойств углей по сравнению с предыдущей стадией метаморфизма.

Углерод, исходя из его односторонней количественной направленности изменения, является основным показателем степени проявления метаморфических процессов. Остальные компоненты $\left(H_{o}, N_{o}, S_{o}, O_{o}\right.$, 
$W)$ дополняют их характеристику. Наиболее активное происходит изменение в элементном составе содержания кислорода и влаги. Содержание водорода существенно снижается на заключительных стадиях метаморфизма. Минимальные изменения наблюдаются в содержании азота и серы. Порядок ранжирования компонентов $H_{o}, N_{o}, S_{o}, O_{o}, W$ по доле их участия в карбонизации (росте $C_{o}$ ) на разных стадиях метаморфизма влияет на химическую активность углей и в этом числе и на склонность к самовозгоранию. Наиболее подвержены самовозгоранию угли, для которых в ряду ранжирования по показателю карбонизации принадлежат ведущие места кислороду, влаге и сере.

В первом приближении склонность шахтопластов к самовозгоранию можно установить, используя результаты технического и элементного анализов углей и их петрографический состав. Многочисленные показатели и методики их определения разрабатывались с целью установления технологических свойств углей. По этой причине не во всех случаях они адекватно характеризуют состав и свойства углей в шахтных условиях. В частности, состав органического вещества $\left(C_{o}, H_{o}\right.$, $N_{o}, S_{o}, O_{o}$ ) определяется на сухую беззольную массу без рассмотрения наличия разных видов влаги. Обычно пласты угля содержат воду в значительно в большем количестве, чем это свойственно природе и геологическому их возрасту. Считается [12], что содержание влаги зачастую не является характерным для установления потребительских свойств показателем. К анализу принимается влага аналитической пробы с крупностью угля менее 0,2 мм.

Проба доводится до воздушно-сухого состояния. Основным ее признаком является крупность измельчения. Добытый уголь теряет на воздухе влагу, находящуюся на внешней поверхности - влагу смачивания. Содержание влаги, соответствующее данному углю (влагосодержание) можно приблизительно оценить с помощью показателя максимальной влагоемкости. Виды влаги не равноценны по прочности связи между водой и углем, и соответственно обладают разными свойствами. Наиболее прочно удерживается углем химически связанная влага, которая не удаляется при определении влажности угля высушиванием и может быть выделена только при разложении минеральной части угля. Ни в один из параметров, характеризующих влажность угля, гидратная вода не входит. Отсутствие четких границ между отдельными видами влаги 
затрудняют их количественное определение. Содержание общей влаги оценивается показателем максимальной влагоемкости угля $W_{\max }^{a f}$. OH рассчитывается на беззольное состояние угля.

Аналогичные имеются трудности при определении содержания серы в органическом и минеральной составляющих. Суммарное содержание $\left(S_{t}^{d}\right)$ называют общей серой. Значение $S_{t}^{d}$ находится для разных шахтопластов в диапазоне $0,2 \div 10 \%$ [12]. Различают несколько основных разновидностей серы (форм):

- сера сульфатная ( $S_{\mathrm{SO}_{4}}^{d}$ в виде сульфатов металлов);

- сера пиритная - в составе неорганической массы угля в виде дисульфидов металлов (пирита и марказита);

- сера органическая $\left(S_{o}\right)$.

Учитывая особенности нахождения влаги и серы в шахтопластах и методы их определения, рассмотрели возможность использования современных результатов технического и элементного анализов для установления склонности углей к самовозгоранию.

Обычно при техническом анализе определяют:

- влагу аналитической пробы $W^{a}, \%$;

- зольность на сухое состояние $A^{d}, \%$;

- выход летучих веществ на сухое беззольное состояние $V^{d a f}, \%$;

- толщину пластического слоя $y$, мм;

- общую серу $S_{t}^{d}, \%$;

- серу сульфатную $S_{\mathrm{SO}_{4}}^{d}, \%$;

- серу пиритную $S_{p}^{d}, \%$.

Элементным анализом предусматривается определение процентного содержания основных компонентов в органическом веществе $\left(C_{o}, H_{o}, N_{o}, S_{o}, O_{o}\right)$ на сухую беззольную массу $(d a f)$.

Не во всех случаях показатели, определенные по результатам технического и элементного анализов можно использовать для установления склонности углей к самовозгоранию без корректировки на условия горных работ в шахтах. В качестве примера рассмотрели (табл. 3) результаты анализа углей для восьми шахтопластов [23].

Содержание углерода $C_{o}$ достаточно точно определяет сумму остальных основных компонентов органического вещества, если исходить из уравнения 


$$
\Sigma H_{o}, N_{o}, S_{o}, O_{o}=100-C_{o}, \% .
$$

В рассматриваемом случае сумма компонентов $H_{o}, N_{o}, S_{o}, O_{o}$ изменялась обратнопропорционально в зависимости от содержания углерода (рис. 1). С ростом значений $C_{\circ}$ с 76,1 до $87,8 \%$ сумма остальных компонентов сокращалась с 20,66 до $12,60 \%$. Невязка баланса согласно расчету по уравнению (4) составляет максимум $1,43 \%$, что указывает на достаточно точное определение суммы основных компонентов $\left(\Sigma H_{o}, N_{o}, S_{o}, O_{o}\right)$. Близкая к функциональной зависимость $(r=-0,99)$ суммы компонентов $\left(\Sigma H_{o}, N_{o}, S_{o}, O_{o}\right)$ в более широком диапазоне изменения $C_{o}(70,40 \div 97,41 \%)$ подтверждена обработкой данных для 162 шахтопластов разных угольных бассейнов [7, 15, 21]. Прямые 1 и 2 в диапазоне изменения $C_{o}$ с 76,1-87,8\% практически совпадают между собой (рис. 1)

Результаты элементного анализа согласно [23] представлены суммой кислорода и азота (табл. 3 ). В диапазоне изменения $C_{o}$ от $67,6 \div 88,0 \%$ содержание $O_{\text {o }}$ определяется $[7,21]$ с достаточной точностью $(r=-0,85)$ при помощи уравнением

$$
O_{o}=76,98-0,812 \cdot C_{o}, \% .
$$

Уравнение (5) получено на основании статистической обработки данных по 177 шахтопластам разных угольных бассейнов. Результаты определения $O_{o}$ по уравнению (5) не противоречат результатам элементного анализа (табл. 3 , рис. 1 прямая 3 и кривая 4) они свидетельствуют, что при $C_{o}=76,1 \div 87,8 \%$ происходит обратнопропорциональное сокращение кислорода с 15,2 до 5,7\%. Содержание водорода оставалось практически постоянным, его среднее значение составляло $5,13 \pm 0,30 \%$. Содержание серы в органической массе колебалось незначительно $(0,60 \div 2,17 \%)$ за исключением пласта $k_{8}$ шахты «Трудовская» $\left(S_{o}=5,33 \%\right)$.

При достаточно низком содержании серы $(1,3 \%)$ в органическом веществе пласта $m_{4}^{0}$ шахты им. Ю.А. Гагарина установлено довольно высокое ее общее содержание ( $S_{p}^{d}=3,75 \%$ ) за счет пиритной серы $\left(S_{p}^{d}=2,41 \%\right)$. Это, несомненно может влиять на пожароопасные свойства пласта $m_{4}^{0}$.

Технический анализ предусматривает определение только влагу аналитических проб $\left(W^{i}\right)$. Их значения не соответствует пластовой влаге, 


\section{Chapter «Engineering sciences»}

\begin{tabular}{|c|c|c|c|c|c|c|c|c|c|c|}
\hline & 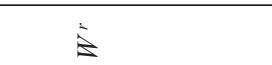 & & 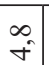 & & & $\therefore$ & & & & \\
\hline & $\bigcup_{0}^{0} \tilde{\sigma}$ & & $\begin{array}{l}0 \\
\stackrel{0}{0}\end{array}$ & $\hat{o}$ & 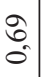 & 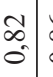 & $\begin{array}{c}\infty \\
\infty \\
\infty \\
0\end{array}$ & 5 & & 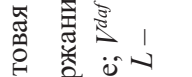 \\
\hline & $\approx$ & $\vec{E}$ & $\begin{array}{l}n \\
n \\
0\end{array}$ & 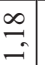 & $\vec{\sigma}$ & in & $\begin{array}{l}g \\
0 \\
0\end{array}$ & 8 & & \\
\hline 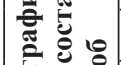 & 90\% ‘' 'иdиш-09dву & $n$ & 0 & - & 0 & in & it & $\infty$ & $\stackrel{\circ}{n}$ & 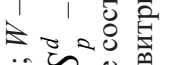 \\
\hline 高雪 & - & in & $a$ & $\cong$ & in & $=$ & $\cong$ & E & \pm & \\
\hline & + & $\infty$ & in & $m$ & 0 & 6 & $\infty$ & $n$ & $m$ & Eี \\
\hline & $a^{-}$ & $\infty$ & $\infty$ & $\infty$ & $\infty$ & \begin{tabular}{c|c}
$\infty$ & \\
$\infty$ &
\end{tabular} & $\infty$ & 6 & $\infty$ & \\
\hline & $5^{\circ}$ & $\underset{\text { di }}{\text { î }}$ & $\begin{array}{l}0 \\
0 \\
0\end{array}$ & $\begin{array}{l}0 \\
\therefore\end{array}$ & $\begin{array}{l}0 \\
\circ\end{array}$ & $\begin{array}{l}= \\
\mathrm{i}\end{array}$ & ch & $?$ & I & \\
\hline : & {$\left[\mathrm{IIz} z^{\prime} \mathrm{L}\right]^{\circ} O$} & $\begin{array}{l}0 \\
\text { i }\end{array}$ & $\begin{array}{c}m \\
\Leftrightarrow \\
\approx\end{array}$ & O. & in & 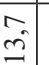 & 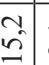 & 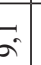 & 6 & \\
\hline 跣 & ${ }^{\circ} \mathrm{N}+{ }^{\circ} \mathrm{O}$ & $\hat{g}$ & $\begin{array}{l}\infty \\
n \\
n\end{array}$ & o. & $\therefore$ & 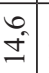 & ב̂ & 8 & ñ & \\
\hline$\frac{\pi}{0}$ & $\mathbb{Z}^{\circ}$ & 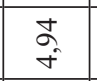 & \begin{tabular}{|l|} 
\\
$\vdots$ \\
$\sigma$ \\
$\dot{\gamma}$
\end{tabular} & $\bar{n}$ & $\begin{array}{c}0 \\
\text { n } \\
n^{2}\end{array}$ & m. & $\begin{array}{c}q \\
q \\
i\end{array}$ & 8 & है & \\
\hline & $0^{\circ}$ & $2^{2}$ & $\begin{array}{l}+ \\
\infty \\
\infty \\
\infty\end{array}$ & $\begin{array}{l} \\
\dot{\infty} \\
\infty\end{array}$ & $\begin{array}{c}\infty \\
\infty \\
\infty \\
\end{array}$ & हे & 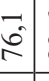 & 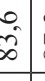 & $\frac{m}{\infty}$ & \\
\hline & $i^{2}$ & $\begin{array}{l}7 \\
0\end{array}$ & \begin{tabular}{l|l|}
$\infty$ \\
0 \\
0
\end{tabular} & \begin{tabular}{l}
$n_{0}$ \\
\hdashline \\
0
\end{tabular} & $\begin{array}{l}0 \\
\vdots \\
0 \\
\end{array}$ & \begin{tabular}{l|l}
$\infty$ \\
0 \\
0
\end{tabular} & $\overrightarrow{0}$ & i & \pm & \\
\hline 竎 & ¿ & O. & $\begin{array}{l}0 \\
0 \\
0\end{array}$ & $\begin{array}{l}0 \\
\vdots \\
0\end{array}$ & $\begin{array}{l}\overrightarrow{0} \\
0 \\
0\end{array}$ & $=$ & $\begin{array}{l}0 \\
\vdots \\
0 \\
0\end{array}$ & 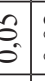 & : & \\
\hline हึ: & is & $\vec{i}$ & $\begin{array}{ll}n \\
0 \\
-1\end{array}$ & $\hat{\circ}$ & $\begin{array}{l} \\
- \\
-\end{array}$ & $\begin{array}{ll} \\
\infty \\
i \\
\end{array}$ & 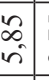 & 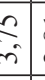 & $\infty$ & \\
\hline 莡 & $\therefore \therefore$ & ' & 1 & สิ & 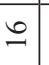 & . & . & D. & $\bar{\imath}$ & \\
\hline 坣 & 咅 & $\begin{array}{l}0 \\
\dot{m} \\
m\end{array}$ & \begin{tabular}{l|}
$m$ \\
2 \\
$m$ \\
$m$
\end{tabular} & 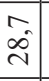 & $\stackrel{m}{m}$ & $\begin{array}{l}\infty \\
\dot{F} \\
\end{array}$ & \begin{tabular}{l|l}
\multirow{2}{*}{} \\
fó \\
\end{tabular} & . & $\stackrel{m}{m}$ & \\
\hline 离 & से & $\stackrel{+}{i}$ & $\stackrel{0}{-}$ & $\hat{m}$ & $\begin{array}{l}0 \\
i \\
i\end{array}$ & के & : & है & $\hat{i}$ & \\
\hline & 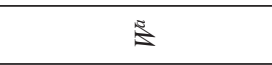 & $\stackrel{\infty}{0}$ & 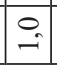 & $\stackrel{1}{=}$ & \pm & 管 & oे & $e^{\infty}$ & 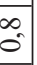 & \\
\hline & IIILL & $\sigma$ & 0 & o & of & $\infty$ & $\infty$ & $\theta$ & 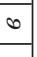 & \\
\hline & 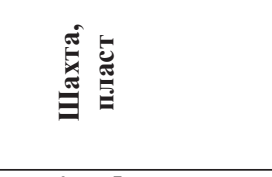 & 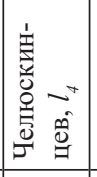 & 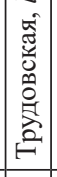 & 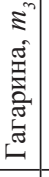 & - & 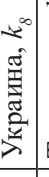 & . & 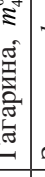 & & \\
\hline & BIIIK BydeIN & $F$ & $F$ & 不 & 㞔 & $E$ & El: & 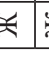 & 不 & \\
\hline
\end{tabular}




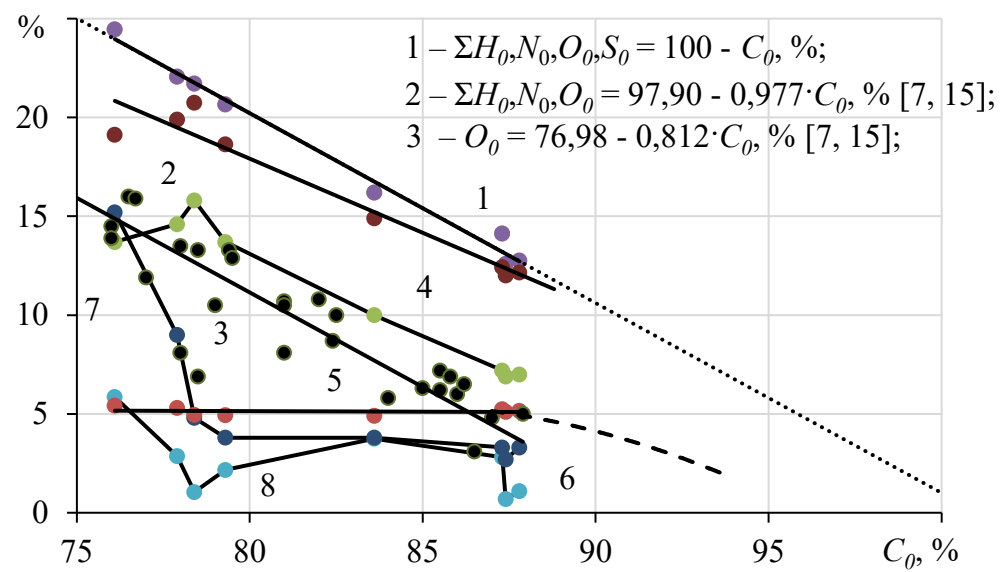

Рис. 1. Изменение основных компонентов органического вещества от содержания углерода согласно [23]

1 - прямая зависимости суммарного содержания водорода $\left(H_{o}\right)$, азота и кислорода $\left(N_{o}+O_{o}\right)$ и серы $\left(S_{o}\right) ; 2$ - прямая зависимости суммарного содержания кислорода, водорода и азота согласно [7, 15]; 3 - прямая зависимости содержания кислорода от углерода в диапазоне $67,6 \div 88,0 \%$ $[7,15] ; 4$ - кривая изменения суммарного содержания азота и кислорода $\left(N_{o}+O_{o}\right)[23] ; 5$ - прямая среднего содержания водорода [23]; 6 - кривая изменения водорода при $C_{o}>88 \%$ согласно $[7,15] ; 7$ - кривая изменения пластовой влаги [24]; 8 - кривая изменения серы [23].

и они немогут быть использованы для оценки склонности шахтопластов к самовозгоранию. В большей степени для этих целей подходит пластовая (рабочая) влажность $W^{\text {. }}$. Средние ее значения известны по изменению параметра $V^{d a f}[24]$. Значения $W^{r}$ существенно превышают показатели $W^{a}$ (табл. 3) и она снижается с 12,0 до 2,7\% по мере увеличения содержания углерода (рис. 1, кривая 7). Исходя из методики установления значений $W^{r}$ они, в большей степени по сравнению с $W^{h}$, определяют склонность шахтопластов к пожароопасности.

Изменение содержания $C_{o}$ в незначительном диапазоне $(76,1 \div 87,8 \%)$ соответствует определенной стадии метаморфических преобразований шахтопластов. Характерной еe особенностью 
является повышенное содержание кислорода по сравнению с другими компонентами органического вещества (рис. 1, кривая 3). По мере усиления процессов карбонизации (росте $C_{o}$ ) доля $O_{o}$ в органическом веществе уменьшается. Еще более быстрыми темпами, при увеличении $C_{o}$ до $78 \%$, происходит сокращение пластовой влаги (кривая 7). Затем содержание пластовой влаги $\left(W^{r}\right)$ стабилизируется на уровне $3-4 \%$. Это свидетельствует о различной химической активности углей при $C_{o}<$ $78 \%$ и $C_{o}=78-88 \%$, вследствие разного соотношения между основными компонентами $\left(O, W^{r}, H_{o}, N_{o}, S_{o}\right)$. О весомости влияния каждого из этих компонентов на процессы самовозгорания можно предполагать по их положению в ряду ранжирования в зависимости от содержания углерода (табл. 4). На рассматриваемой примерно одинаковой стадии преобразования шахтопластов $\left(C_{o}<88 \%\right)$ и преобладающей доле кислорода происходит изменение соотношения между остальными компонентами органического вещества. Изменение положения $W^{r}, H_{o}$, $N_{o}$ и $S_{o}$ в ряду ранжирования свидетельствует о наличии существенных отличий между рассматриваемыми пластами по склонности их к самовозгоранию. Можно констатировать, что уголь пласта $k_{8}$ шахты «Трудовская» является наиболее химически активным. Он содержит максимальное количество кислорода (15,2\%), серы (5,33\%) при пластовой влажности 12,0\% (табл. 3).

С остальными шахтопластами пласт $k_{8}$ шахты «Трудовская» объединяет только преимущественное содержание кислорода в органическом веществе. Отличительными признаками являются разные соотношения $O_{o}$ с остальными компонентами $\left(W^{r}, H_{o}, N_{o}, S_{o}\right)$, что следует из их разного положения в рядах ранжирования (табл. 4). Ряды ранжирования по содержанию компонентов в органическом веществе еще в большей степени изменяются при содержании углерода более 90\%. На конечной стадии преобразования углей $\left(C_{o} \approx 97 \div 98 \%\right)$, исходя из статистических зависимостей $(7,15,21)$, ряд ранжирования компонентов в малосернистых углях будет примерно соответствовать следующему порядку их расположения: $N_{o}, S_{o}, H_{o}, W^{r}$ и $O_{o}$. Он диаметрально отличается от рядов ранжирования (табл. 4). Кислород перемещается на последнее место в ряду ранжирования, а азот - на первое, что свидетельствует о минимальной химической активности углей при $C_{o} \approx 97 \div 98 \%$. 
Таблица 4

Изменение ранжирования содержания компонентов

в органическом веществе в зависимости от карбонизации (росте $C_{o}$ ) углей

\begin{tabular}{|c|c|c|c|c|c|c|c|c|}
\hline $\begin{array}{c}\text { Компоненты } \\
\text { органического } \\
\text { вещества }\end{array}$ & \multicolumn{7}{|c|}{ Положение в ряду ранжирования } \\
\cline { 2 - 10 } & $\mathbf{7 6 , 1}$ & $\mathbf{7 7 , 9}$ & $\mathbf{7 8 , 4}$ & $\mathbf{7 9 , 3}$ & $\mathbf{8 3 , 6}$ & $\mathbf{8 7 , 3}$ & $\mathbf{8 7 , 4}$ & $\mathbf{8 7 , 8}$ \\
\hline $\mathrm{O}_{o}$ & 1 & 1 & 1 & 1 & 1 & 1 & 1 & 1 \\
\hline $\mathrm{W}^{\mathrm{r}}$ & 2 & 2 & 3 & 3 & 3 & 3 & 3 & 3 \\
\hline $\mathrm{S}_{o}$ & 4 & 4 & 5 & 4 & 4 & 4 & 5 & 3 \\
\hline $\mathrm{H}_{o}$ & 3 & 3 & 2 & 2 & 2 & 2 & 2 & 2 \\
\hline $\mathrm{N}_{o}$ & 5 & 5 & 4 & 5 & 5 & 5 & 4 & 4 \\
\hline
\end{tabular}

Напримере изменения элементного состава органического вещества $\left(C_{o}, H_{o}, N_{o}, S_{o}, W^{r}\right)$ на всех стадиях метаморфических преобразований шахтопластов показаны отличительные особенности химической активности углей. Ее достоверное определение в условиях ведения горных работ возможно при дополнительном использовании уже имеющихся результатов элементного и технического анализов углей. Методика определения химической активности углей при отработке каждого шахтопласта должна учитывать количественные соотношения между основными компонентами органического вещества, а также доли их участия в карбонизации. При разработке такой методики необходимо также учитывать предыдущий индивидуальный опыт ведения горных работ на рассматриваемом шахтопласте. При разработке методики прогноза условий возникновения эндогенных пожаров необходимо, по возможности, привлекать данные о петрографическом составе углей (табл. 3). Это даст возможность получить дополнительные сведения о склонности углей к самовозгоранию. Например, наличие фюзинита характеризует повышенное содержание кислорода и более низкое водорода. Вследствие этого уголь в большей степени склонен к самонагреванию и самовозгоранию [25]. Значение петрографических характеристик состава угля позволяет более обосновано решать практические задачи. После установления влияющих факторов первого блока, необходимо определить опасные места в пределах шахтного поля по вероятности возникновения эндогенных пожаров. Технологическая 
схема шахты в значительной мере связана с горно-геологическими условиями залегания угольных пластов (факторами второго блока). Она определяет способ и схему вскрытия, подготовку запасов к выемке в шахтном поле, транспорт, системы разработки, порядок отработки шахтного поля и выемочных участков, схемы их проветривания. На основании технологической схемы шахты устанавливаются места и длительность контакта рудничной атмосферы с углем.

Вероятность возникновения очагов самонагревания и самовозгорания устанавливается в отдельных частях шахтного поля с учетом размеров возможных скоплений отбитого угля, его нарушенности в краевых частях массивов или целиков под влиянием повышенного горного давления и геологических нарушений. Для каждого возможного места возникновения очага самовозгорания определяются условия и допустимый период времени контакта угля с рудничной атмосферой. Такие расчеты возможны после установления факторов второго блока, влияющих на возникновение эндогенных пожаров на протяжении всего периода эксплуатации угольного предприятия.

Большинство произошедших эндогенных пожаров связано с ведением очистных работ при эксплуатации выемочных участков или после их остановки. Около $80 \%$ эндогенных пожаров возникло при выемке пластов не на полную мощность или попадании угля сближенных пластов в зону сдвижения пород с разрывом сплошности. При таких условиях ведение очистных работ происходил длительный контакт угля с рудничной атмосферой.

Третий блок факторов, снижающих вероятность возникновения очагов самовозгорания, должен учитывать технологию ведения очистных работ и схемы проветривания выемочных участков при их эксплуатации и после остановки. Третий блок влияющих факторов наименее изучен. Нормативной базой Украины рекомендуется выемку угля производить при скорости подвигания очистных забоев не менее 50 м/мес, а в России - не менее 90 м/мес [26]. Считается, что при таких скоростях подвигания очистных забоев в выработанном пространстве очаги самовозгорания не успевают образоваться. Эти предположения не подтвердились в ввиду произошедших крупных аварий, с тяжелыми последствиями, связанными с возникновением 
очагов самовозгорания при скоростях подвигания очистных забоев 200-300 м/мес [27]. Вследствие высокой интенсивности ведения очистных работ возрастаетопорноегорноедавление, воздействующеена краевые части угольных пластов. В настоящее время при планировании горных работ и при расследовании произошедших в шахтах аварий не принимается во внимание влияние горного давления (сдвижение пород) на возникновение очагов самонагревания угля. Третий блок факторов влияющих на возникновение очагов самовозгорания также должен непосредственно учитывать особенности технологических процессов при добыче угля на выемочных участках и проведении горных выработок.

\section{4. Выводы}

На основании проведенных исследований установлены три блока факторов, определяющих склонность шахтопластов к эндогенным пожарам. Отсутствие устойчивой корреляционной зависимости между влияющими факторами отдельных блоков, позволило разработать следующую методику логической последовательности прогноза склонности шахтопластов к возникновению эндогенных пожаров. Она заключается в следующем:

- устанавливается химическая активность угля для соответствующей стадии метаморфического преобразования шахтопласта. Для этих целей используются результаты технического и элементного анализов углей и их петрографический состав. Они позволяют установить соотношения между основными компонентами органического вещества - углеродом, кислородом, водородом, азотом, серой и пластовой влагой. Склонность к самонагреванию и самовозгоранию определяют содержания кислорода, серы и пластовой влаги. На основании ранжирования всех компонентов органического вещества устанавливается склонность угля к самовозгоранию;

- исходя из горно-геологических условий и технологической схемы шахты определяют опасные места по вероятности возникновения эндогенных пожаров в пределах шахтного поля. Рассматривается способ и схема вскрытия, подготовка запасов к выемке, транспорт, система разработки, порядок отработки шахтного поля и выемочных участков, схемы их проветривания. Определяются места и длительность 
возможного контакта рудничной атмосферы с отбитым углем и в зонах его нарушения в пластах под влиянием горного давления или геологических нарушений;

- обосновывается технология очистных работ и проведение горных выработок. Учитывается полнота выемки разрабатываемого пласта, управление горным давлением и возможность попадания сближеных пластов в зону сдвижения пород с разрывом сплошности, допустимые потери угля и условия его складирования в магазинах или бункерах.

При таком подходе устанавливаются реальная химическая активность углей по их элементному содержанию на разных стадиях метаморфических преобразований пластов и дифференцированно определяются конкретные места в шахтном поле длительных контактов рудничной атмосферы с углем. Это способствует более качественному автоматизированному контролю за состоянием рудничной атмосферы и выявлению очагов самовозгорания на ранних стадиях их образования.

\section{5. Благодарность}

Автор выражает благодарность и глубокую признательность д.т.н., профессору, заведующему кафедрой горного дела Восточноукраинского национального университета имени Владимира Даля Антощенко Николаю Ивановичу за советы и ценные замечания при работе над данной статьей.

\section{Список литературы:}

1. Лапин А.А., Васякова А.В. Геолого-углехимическая характеристика пластов самовозгорающихся углей в Донецком бассейне. Уголь Украины. 1974. № 1. С 43-45.

2. Чумак А.С. О разработке пластов угля, склонных к самовозгоранию. Уголь Украиныл. 1973. № 11. С. 53.

3. Пашковский П.С., Костенко В.К., Заславский В.П., Хорольский А.Т., Заболотный А.Г. [и др.]. Эндогенные пожары на угольных шахтах Донбасса. Предупреждение и тушение. Инструкция. Издание официальное: КД 12.01.401-96. Донецк : НИИГД, 1997. 68 с.

4. Греков С.П., Пашковский П.С., Орликова В.П. Механизм образования очагов самовозгорания угля в краевой части угольного пласта. Уголь Украины. 2014. № 10. С. 46-50.

5. Склонность к самовозгоранию углей, шахтных пород и отходов углеобогащения. Методика определения: КД 12.01.04.009-2000 : Утв. Минтопэнерго Украины 26.09.2000 г. Донецк, 2000. 28 с. 
6. Кошовский Б.И., Пашковский П.С., Карасева В.В. Пути повышения достоверности определения склонности углей к самовозгоранию. Уголь Украины. 2008. № 12. С. 45-47.

7. Антощенко Н.И., Тарасов В.Ю., Захарова О.И. Анализ пожароопасных участков (зон) в угольных шахтах и причины самовозгорания углей. Technology audit and production reserves. 2019. T. 6, № 3(50). С. 14-18. DOI: $10.15587 / 2312-8372.2019 .185953$

8. Пашковский П.С. и др. Метод определения группы эндогенной пожароопасности шахтопластов. Уголь Украиныл. 2016. № 4-5. С. 51-55.

9. Руководство по предупреждению и тушению эндогенных пожаров на угольных шахтах Украины: КД 12.01.402 - 2000. Донецк : НИИГД, 2000. 216с.

10.Греков С.П., Зинченко И.Н., Шайтан И.А. и [др.] Комплексный показатель пожароопасности угольных пластов. Уголь Украины. 2007. № 1. С. 32-34.

11.Греков С.П., Пашковский П.С., Зинченко И.Н., Головченко Е.А. Определение группы пожарной опасности шахтопластов. Уголь Украиныл. 2008. № 8. C. $25-26$.

12. Авгушевич И.В., Сидорук Е.И., Броновец Т.М. Стандартные методы испытания углей. Классификации углей. Москва : «Реклама мастер». 2019. 576 с.

13.ГОСТ 25543 - 2013. Межгосударственный стандарт. Угли бурые, каменные и антрациты. Классификация по генетическим и технологическим параметрам. Издание официальное. Москва : Стандартинформ, 2014. 19 с.

14.ГОСТ 17070-2014. Угли. Термины и определения. Межгосударственный стандарт. Москва : Стандартинформ, 2015. 17 с.

15. Антощенко Н.И., Томалак Н.В. и [др.] Влияние температуры на степень метаморфиззма ископаемых углей. Уголь Украины. 2002. № 7. С. 36-38.

16.ГОСТ 6382 - 2001 (ИСО 562-98, ИСО 5071-1-97). Межгосударственный стандарт. Топливо твёрдое минеральное. Методы определения выхода летучих веществ. Издание официальное. Межгосударственный совет по стандартизации, метрологии и сертификации. Минск, 2002. 13 с.

17.Голинько В.И., Алексеенко С.А., Смоланов И.Н. Аварийно-спасательные работы в шахтах : учеб. пособие / за ред. В.И. Голинько. Д. : Лира, 2011. $479 \mathrm{c}$.

18. Успенский В.А. Опыт материального баланса процессов, происходящих при метаморфизме угольных пластов. Нефтегазовая геология. Теория и практика. 2006. T. 1. С. 1-10.

19.Акиньшин Б.Т. Метаморфизм и взаимосвязь микро- и макропористой структуры, влажности угля с газоносностью пластов. Уголь Украины. 1985. C. 37-39.

20. Кошовский Б.И., Орликова В.П. Влияние влаги на процесс низкотемпературного окисления угля. Уголь Украины. 2015. № 3-4. С. 39-43.

21. Антощенко Н.И., Шепелевич В.Д. Метан в угольных пластах от образования до выделения : Монография. Алчевск : ДонГТУ, 2006. 267 с.

22. Давиденко В.А., Антощенко Н.И., Сятковский С.Л. О связи влажности углей с показателями их степени метаморфизма. Вестник МАНЭБ Выпуск Восточно-Украинского отделения. 2001. № 9(45). С. 7-12. 
23. Бутузова Л.Ф. и др. Взаимосвязь между технологическими свойствами углей и составом экстрактов. Вестник Донеикого национального технического университета. 2016. № 1. С. 13-20.

24. Медведев Э.Н., Саранчук В.И., Качан В.Н. Оценка пылеобразующей способности углей в ряду метаморфизма. Уголь Украины. 1984. № 9. С. 32-33.

25.Бондаренко B.I., Кузьменко О.М., Грядущий Ю.Б., Гайдук В.А., Колоколов О.В. Технологія підземної розробки пластових родовищ корисних копалин : Підруч. для студ. вищ. навч. закл. Д. : Нац. гірн. ун-т, 2005. 708 с.

26.Инструкция по предупреждению и тушению подземных эндогенных пожаров в шахтах Кузбасса. Кемерово : ВостНИИ, 2007. С. 82.

27. Скрицкий В.А. Причины взрывов метана в высокопроизводительных угольных шахтах Кузбасса. Инноватика и экспертиза: научные труды. 2017. № 2. C. 171-180.

\section{References:}

1. Lapin, A.A. and Vasyakova, A.V. (1974). Geology-coal-chemical description of layers of self-ignitional coals in the Donetsk field. Coal of Ukraine, no. 1, pp. $43-45$.

2. Chumak, A.S. (1973). About exploitationt of the layers of coal, inclined to spontaneous combustion. Coal of Ukraine, no. 11, p. 53.

3. Pashkovskiy, P.S., Kostenko, V.K., Zaslavskiy, V.P. (et al.) (1997). KD 12.01.401-96 Endogennyye pozhary na ugol'nykh shakhtakh Donbassa. Preduprezhdeniye i tusheniye. Instruktsiya. Izdaniye ofitsial'noye [KD 12.01.401-96 Endogenous fires in the coal mines of Donbass. Prevention and suppression. Instructions. Official publication]. Donetsk: NIIGD.

4. Grekov, S.P., Pashkovskiy, P.S., Orlikova, V.P. (2014). The mechanism of formation of foci of spontaneous combustion of coal in the edge of the coal seam. Coal of Ukraine, no. 10, pp. 46-50.

5. Mintopenergo Ukrainy (2000). KD 12.01.04.009-2000 Sklonnost' k samovozgoraniyu ugley, shakhtnykh porod i otkhodov ugleobogashcheniya. Metodika opredeleniya [KD 12.01.04.009-2000 The tendency to spontaneous combustion of coals, mine rocks and waste coal preparation. Determination method]. Donetsk.

6. Koshovskiy, B.I., Pashkovskiy, P.S., Karaseva, V.V. (2008). Ways to improve the reliability of determining the propensity of coal to spontaneous combustion. Coal of Ukraine, no. 12, pp. 45-47.

7. Antoshchenko, M., Tarasov, V., \& Zakharova, O. (2019). Analysis of fire and hazardous sites (zones) in coal mines and the causes of coal self-ignition. Technology audit and production reserves, T. 6, no. 3(50), pp. 14-18.

8. Pashkovskiy, P.S. (et al.) (2016). Method for determining the group of endogenous fire hazard of mine layers. Coal of Ukraine, no. 4-5, pp. 51-55.

9. Minpalyvenergo Ukrainy (2001). KD 12.01.402-2000 Rukovodstvo po preduprezhdeniiu i tusheniiu endogennykh pozharov na ugolnykh shakhtakh Ukrainy [KD 12.01.402-2000 Guidance from prevention and extinguishing of endogenous fires on the coal mines of Ukraine, NIIGD „Respirator", Donetsk. 
10. Grekov, S.P., Zinchenko, I.N., Shaytan I.A. (et al.) (2007). Complex index of coal layers risk hazard. Coal of Ukraine, no. 1, pp. 32-34.

11. Grekov, S.P., Pashkovskiy, P.S., Zinchenko, I.N., Golovchenko, E.A. (2008). Determination of the fire hazard group of mines. Coal of Ukraine, no. 8, pp. 25-26.

12.Avgushevich, I.V., Sidoruk, E.I., Bronovets, T.M. (2019). Standard Test Methods for Coals. Coal classification. Moscow: «Reklama master». (in Russian)

13. GOST 25543-2013. Ugli burye, kamennye i antratsity. Klassifkatsiya po geneticheskim i tekhnologicheskim parametram [State standard 25543-2013 Lignites, coals and antracites. Classification by genetic and technological parameters]. Moscow: Standartinform, 2014. 18 p.

14. GOST 17070 - 2014. Ugli. Terminy i opredeleniya [State standard 17070 2014. Soals. Terms and difinitions]. Moscow: Standartinform, 2015. 17 p.

15. Antoshchenko, N.I., Tomalak, N.V. (2002). Influence of temperature on the degree of metamorphism of fossil coals. Coal of Ukraine, no. 7, pp. 36-38.

16. GOST 6382 - 2001. Toplivo tverdoe mineral'noe. Metody opredeleniya vykhoda letuchikh veshchestv. [State standard 6382 - 2001. Solid mineral fuel. Methods for determination of volatile matter yield]. Moscow: Standartinform, 2002. 13 p.

17. Golin'ko, V.I. Alekseenko, S.A., Smolanov, I.N. (2011). Avariyno-spasatel'nye raboty v shakhtakh [Mine rescue operations]. D.: Lira.

18. Uspenskiy, V.A. (2006). Opyt material'nogo balansa protsessov, proiskhodyashchikh pri metamorfizme ugol'nykh plastov [Experience of material balance of processes occurring during metamorphism of coal seams]. Petroleum GeologyTheoretical and Applied Studies, no. 1, pp. 1-10.

19. Akin'shin B.T. (1985) Metamorfizm i vzaimosvyaz' mikro- i makroporistoy struktury, vlazhnosti uglya s gazonosnost'yu plastov [Metamorphism and interrelation of micro- and macroporous structure, moisture content of coal with gas content of seams]. Coal of Ukraine, pp. 37-39.

20. Koshovskiy, B.I., Orlikova, V.P. (2015). Vliyanie vlagi na protsess nizkotemperaturnogo okisleniya uglya [Influence of moisture on the process of low-temperature oxidation of coal]. Coal of Ukraine, no. 3-4, 39-43.

21. Antoshhenko, N.I., Shepelevich, V.D. (2006). Methane in coal seams from formation to emission. [Metan v ugol'nyh plastah ot obrazovanija to vydelenija]. Alchevsk: DonGTU, 267 p. (in Russian)

22. Davidenko, V.A., Antoshchenko, N.I., Syatkovskiy, S.L. (2001). O svyazi vlazhnosti ugley s pokazatelyami ikh stepeni metamorfizma [On the relationship between the moisture content of coals and indicators of their degree of metamorphism]. Vestnik MANEB Vypusk Vostochno-Ukrainskogo otdeleniya, no. 9(45), pp. $7-12$

23. Butuzova, L.F. (et al.) (2016). Vzaimosvyaz' mezhdu tekhnologicheski-mi svoystvami ugley i sostavom ekstraktov [Possibilities of coal technological properties assessment by the extracts composition]. Vestnik Donetskogo natsional'nogo tekhnicheskogo universiteta, no. 1, pp. 13-20.

24. Medvedev, E.N., Saranchuk, V.I., Kachan, V.N. (1984) Otsenka pyleob-razuyushchey sposobnosti ugley $\mathrm{v}$ ryadu metamorfizma [Evaluation of the 
dust-forming ability of coals in the series of metamorphism]. Coal of Ukraine, no. 9 , pp. 32-33.

25. Bondarenko, V.I., Kuz'menko, O.M., Gryadushchiy, Yu.B. (et al.) (2005). Tekhnologiya pidzemnoï rozrobki plastovikh rodovishch korisnikh kopalin [Technology of underground development of reservoir mineral deposits]. D.: Nats. girn. un-t. (in Ukrainian)

26. FGUP RosNIIGD (et al.). (2007). Instruktsiya po preduprezhdeniyu i tusheniyu podzemnykh endogen-nykh pozharov v shakhtakh Kuzbassa [Instructions for the prevention and extinguishing underground endogenous fires in coal mines in Kuzbass]. Kemerovo.

27. Skritskiy, V.A. (2017). Prichiny vzryvov metana v vysokoproiz-voditel'nykh ugol'nykh shakhtakh Kuzbassa [Causes of methane explosions in highly productive coal mines of Kuzbass]. Innovatics and Expert Examination, vol. 2, pp. 171-180. 